\title{
Dye removal abilities of the mesophilic and thermophilic biomass: a kinetics study
}

\author{
Sayilgan E. \\ Department of Environmental Engineering, Suleyman Demirel University, 32260 Isparta, Turkey \\ Received: 31/01/2018, Accepted: 08/05/2018, Available online: 07/08/2018 \\ *to whom all correspondence should be addressed: e-mail: eminesayilgan@sdu.edu.tr
}

\begin{abstract}
Mesophilic biomass and thermophilic biomass samples were isolated and used to remove Dorasyn Red dye from aqueous solutions. The biosorption kinetics of dye uptake by four different types of biomass at three temperatures $\left(20,30\right.$, and $\left.40^{\circ} \mathrm{C}\right)$ were investigated using pseudo-first order kinetics, pseudo-second order kinetics, intraparticle diffusion, Elovich, and Bangham models. The pseudosecond-order kinetics model and the first stage of the intraparticle diffusion model were effective in describing the experimental kinetics data. The biosorption results showed that the mesophilic biomass samples could be useful for removing dye under acidic conditions.
\end{abstract}

Keywords: Biomass, dye, kinetics, mesophilic, thermophilic.

\section{Introduction}

The extensive use of dyes in many different settings such as the textile, paint, and pulp industries results in the production of coloured wastewater effluents that can cause environmental pollution (Akar et al., 2010; Mona et al., 2011). It is therefore necessary to remove dyes from wastewater before it is discharged. However, it is extremely difficult to treat wastewater containing dyes because of the complex aromatic structures and synthetic origins of many dyes, and because such wastewater is likely to have a low BOD and a high COD (Baskaralingam et al., 2006). Conventional processes used to remove dyes from wastewater include adsorption, advanced oxidation, coagulation/flocculation, electrochemical destruction, electroflotation, electrokinetic coagulation, ion exchange, irradiation, membrane filtration, and precipitation. While these methods can remove dyes from wastewater, they are quite expensive and can be difficult to implement from a technical point of view (Asgher and Bhatti, 2012).

Biological processes for removing dyes from wastewater offer environmental and economic advantages over conventional physicochemical processes (Kaushik and Malik, 2011). Many microorganisms have been identified that are capable of decolourizing a wide range of dyes and other contaminants, these have included actinomycetes, algae, bacteria, fungi, plants, and yeasts (Seesuriyachan et al., 2007; Deive et al., 2010; Kurade et al., 2012). Certain types of biomass contain organisms that can be used to degrade dyes in wastewater and using biomass to treat wastewater offers advantages in that the fermentation techniques used are relatively simple and the growth media are inexpensive (Mahanpoor et al., 2005). Pearce et al. (2003) used whole bacterial cells to decrease the concentrations of water-soluble dyes in wastewater from a textile dyeing process. Seesuriyachan et al., (2007) investigated the effects of a range of factors on the decolourization of wastewater by Lactobacillus casei TISTR 1500. Oturkar et al., (2011) found that Bacillus lentus BI377 could degrade about $95 \%$ of the Reactive Red 120 dye present in wastewater. A literature survey revealed several studies of the extraction of metals using mesophilic and thermophilic bacteria. Deveci et al., (2004) studied the bioleaching of complex zinc sulphides by mesophilic and thermophilic bacteria. Taha et al., (2014) investigated the use of thermophilic fungi to decolourize a mixture of high concentrations of azo and anthraquinone dyes at $55^{\circ} \mathrm{C}$.

The aim of our study was to assess the kinetics of the removal of a dye from aqueous solutions using mesophilic and thermophilic biomass samples. From a literature survey we found hardly any studies in which the abilities of mesophilic and thermophilic biomass isolated from whey were compared in terms of their removal of dye from aqueous solutions. We first isolated mesophilic (MMRS and MM17) and thermophilic (TMRS and TM17) biomass, then we determined the effects of the $\mathrm{pH}$ and biomass concentration on the decolourization achieved. Finally, we investigated the effect of the temperature on the decolourization kinetics when the four different types of biomass were used.

\section{Materials and methods}

\subsection{Preparation of solutions}

The Dorasyn Red dye (DR) used in this study was kindly provided by a textile factory in Isparta, Turkey. DR is classified as an anionic dye. The absorbance of a solution of the dye was measured over the visible range, allowing us to determine the absorption maximum. A standard curve was obtained by measuring the absorbance of solutions containing different concentrations of DR at $465 \mathrm{~nm}$ using a Hach DR-5000 spectrophotometer (Hach Lange, 
Düsseldorf, Germany). A 1,000 $\mathrm{mg} \mathrm{L}^{-1}$ stock solution of DR in distilled water was prepared, and solutions with the desired concentrations were prepared by diluting this stock solution. The stock solution was kept in a $2 \mathrm{~L}$ plastic volumetric flask at $4{ }^{\circ} \mathrm{C}$. All the other chemicals (including $\mathrm{HCl}$ and $\mathrm{NaOH}$ ) were of analytical grade and were purchased from Merck (Darmstadt, Germany).

\subsection{Biomass preparation}

A whey sample was obtained from a dairy factory in Isparta and was stored at $-80^{\circ} \mathrm{C}$. Mesophilic and thermophilic Lactobacillus and Lactococcus organisms were isolated from the whey and similar isolation and inoculation methods were applied as described previously (Sofu et al., 2015; Ramyakrishna and Sudhamani, 2017). Four different biomass samples were used in this study. Mesophilic Lactobacilli (later called MMRS) and mesophilic Lactococci (later called MM17) cultures were grown in MRS broth and M17 broth (both from Merck), respectively, at $37^{\circ} \mathrm{C}$ for 48 h. Thermophilic Lactobacilli (later called TMRS) and thermophilic Lactococci (later called TM17) cultures were grown under anaerobic conditions in MRS broth and M17 broth, respectively, at $60^{\circ} \mathrm{C}$ for $48 \mathrm{~h}$. The biomass cultures were then centrifuged at 10,000 rpm for $10 \mathrm{~min}$ in a 5804R centrifuge (Eppendorf, Hamburg, Germany), and the pellets and supernatants were collected separately. The pellets were freeze-dried and stored at $-20{ }^{\circ} \mathrm{C}$. These freeze-dried biomass samples were used in the experiments.

\subsection{Biosorption kinetics experiments}

The kinetics of DR removal by the biomass samples were assessed by experiments using a biomass dose of $2.5 \mathrm{~g} \mathrm{~L}^{-1}$ and a DR concentration of $100 \mathrm{mg} \mathrm{L}^{-1}$ at $\mathrm{pH} \mathrm{3}$, and at different temperatures $\left(20,30\right.$, and $\left.40^{\circ} \mathrm{C}\right)$. Reaction times of $0,0.5,1,2,4,8$, and $24 \mathrm{~h}$ were used for the kinetics experiments. After the selected reaction time each sample was centrifuged at $10,000 \mathrm{rpm}$ for $5 \mathrm{~min}$ to remove the biomass, then the intensity of the colour in the solution was determined using a Hach Lange DR-5000 spectrophotometer.

The amount of DR adsorbed at equilibrium, $q_{\mathrm{e}}\left(\mathrm{mg} \mathrm{g}^{-1}\right)$, was calculated using Equation 1,

$$
q_{e}=\frac{\left(C_{0}-C_{e}\right)}{W} v
$$

where $C_{0}$ and $C_{e}\left(\mathrm{mg} \mathrm{L}^{-1}\right)$ are the initial and equilibrium DR concentrations, respectively, $\mathrm{V}$ is the volume of solution ( $\mathrm{L}$ ), and $w$ is the dry mass of the biomass used $(\mathrm{g})$.

\subsection{Analytical methods}

The initial dye concentration in each solution was determined by measuring the absorbance at $465 \mathrm{~nm}$ using a Hach Lange DR-5000 spectrophotometer. After being used in an experiment the MMRS, TMRS, MM17, and TM17 samples were dried overnight at $60{ }^{\circ} \mathrm{C}$. The Fourier transform infra-red (FTIR) spectra of the biomass samples were obtained using a Perkin-Elmer BX IR spectrometer (Perkin-Elmer, Waltham, MA, USA). Scanning electronic microscopy (SEM), performed using an XL-30 S FEG instrument (Phillips, Eindhoven, The Netherlands), was used to examine the morphologies of the MMRS, TMRS, MM17, and TM17 biomass samples before and after the experiments. The FTIR spectra and SEM images of all of the mesophilic and thermophilic biomass samples were similar throughout the study, therefore only the characteristics of the thermophilic biomass samples (TMRS and TM17) are given here.

\section{Results and Discussions}

\subsection{Characterization of the biomass samples and analysis of the DR removal mechanism}

There is great potential for using certain types of biomass as sorbents because of their physicochemical characteristics. Relatively complex methods, including surface adsorption, ion exchange, complexation, complexation and chelation, and micro-precipitation, are typically used to remove dye from wastewater (Banks and Parkinson, 1992; Chu and Chen, 2002; Gupta and Suhas, 2009). The mechanisms involved in decolourizing dye solutions can generally be classed as electrostatic interactions (Liu et al., 2001). The solution $\mathrm{pH}$, the structural properties of the dye and the biomass, ionic exchange processes, and electrostatic repulsion can play important roles in the biosorption of dyes (Fan et al., 2012). For example, we used an anionic DR dye in this study, and the removal efficiency at the original $\mathrm{pH}$ of the solution (approximately $\mathrm{pH}$ 7) was rather poor because the sites on the biosorbent were negatively charged. The removal efficiency was higher at acidic $\mathrm{pH}$ values because of the presence of $\mathrm{H}^{+}$ions in the solution.

The FTIR spectra of the (a) TMRS and (b) TM17 after the dye removal experiments are shown in Fig. 1 and were used to identify the functional groups on the biomasses and to determine the dye removal mechanism.

The TMRS and TM17 FTIR spectra each contained $-\mathrm{OH}$ and $-\mathrm{NH}$ stretching bands at 3291-3405 $\mathrm{cm}^{-1}$, an $-\mathrm{OH}$ stretching band at $2369 \mathrm{~cm}^{-1}$, a $\mathrm{C}=\mathrm{C}$ aromatic stretching vibration band at $1655 \mathrm{~cm}^{-1}$, and an $\mathrm{S}=0$ stretching vibration band at $1077 \mathrm{~cm}^{-1}$ (Parshetti et al., 2010). An asymmetric stretching band at around $1650 \mathrm{~cm}^{-1}$ was also found in each spectrum, suggesting the presence of carboxyl groups. The carboxyl, hydroxyl, and amino groups found are the sites at which most sorption processes occur (Zhang et al., 2009; Sayilgan and Cakmakci, 2013). Kurade et al., (2012) found similar peaks for a bacteria-yeast consortium, BL-GG, used to decolourize textile effluent.

The SEM results also showed that the original TMRS and TM17 were net-like structures with angular shapes, whereas the SEM images of the TMRS and TM17 after they had been used to remove DR dye from solution showed that their structures had changed significantly (figures not shown). The pores of the biomass samples had become coated with dye, making the originally rough surfaces become smoother, which is consistent with results previously described (Lata et al., 2008; Pengthamkeerati et al., 2008). The TMRS biomass contained both bacillus and coccus structures. The results of the kinetics experiments were used to attempt to determine the 
mechanisms involved in the removal of the dye by the biomass samples. The biosorption process was found to be strongly dependent on a wide range of biosorption

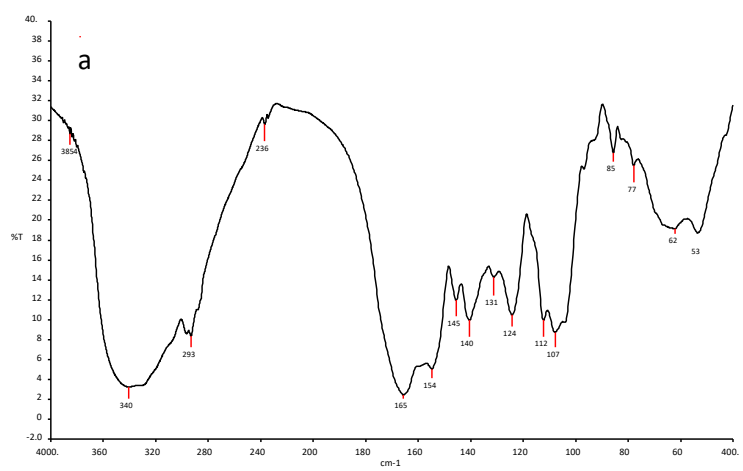

mechanisms, and boundary layer diffusion was found to have a particularly strong influence on biosorption.

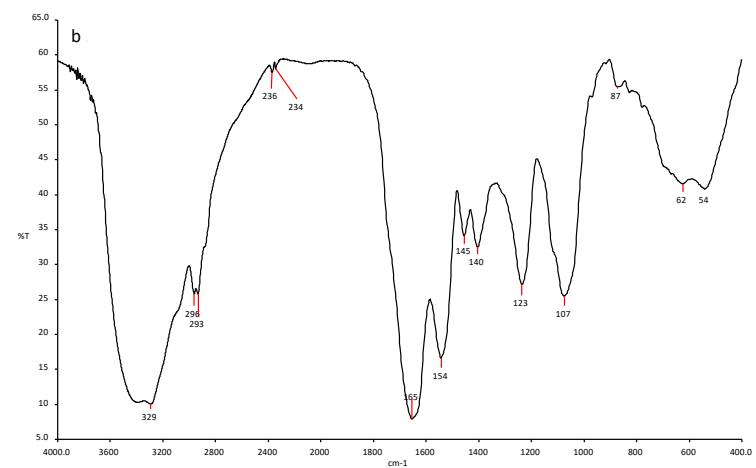

Figure 1. Fourier transform infra-red spectra of the (a) TMRS and (b) TM17 biomass samples after they had been used to remove Dorasyn Red from solution

\subsection{Biosorption kinetics}

Kinetics studies are commonly used to help understand the mechanisms involved in biosorption processes (Akar and Divriklioglu, 2010; Xi et al., 2013) and to determine which mechanisms control the efficiency of the biosorption process (Annadurai et al., 2008). Several kinetics models can be used to determine which mechanism controls the biosorption processes. Langergren's rate equations are commonly used to model the biosorption of a solute from a liquid (Annadurai et al., 2008). We tested our kinetics data acquired at different temperatures against pseudofirst-order kinetics, pseudo-second-order kinetics, intraparticle diffusion, Elovich, and Bangham (pore diffusion) models. The constants for these models and the correlation coefficients for the relationships between the models and the experimental data are calculated (Table 1).

\subsubsection{Pseudo-first-order kinetics model}

The pseudo-first-order kinetics equation for a simple biosorption kinetics test is shown in Equation 2.

$$
\frac{\mathrm{d}_{\mathrm{qt}}}{\mathrm{q}_{\mathrm{t}}}=\mathrm{k}_{1}\left(\mathrm{q}_{\mathrm{eq}}-\mathrm{q}_{\mathrm{t}}\right)
$$

Equation 2 becomes linear when it is integrated using the initial condition of $q_{t}=0$ at $t=0$ and $q_{t}=q_{t}$ at $t=t$ (Ho and McKay, 1998), giving the pseudo-first-order kinetics model shown in Equation 3,

$$
\log \left(\mathrm{q}_{\mathrm{e}}-\mathrm{q}_{\mathrm{t}}\right)=\frac{\log \left(\mathrm{q}_{\mathrm{e}}-\mathrm{k}_{1}\right)}{2.303} \mathrm{t}
$$

where $q_{\mathrm{e}}$ and $q_{\mathrm{t}}$ are the biosorption capacities $\left(\mathrm{mg} \mathrm{g}^{-1}\right)$ of the biomass at equilibrium and at time $t$, respectively, and $k_{1}$ is the equilibrium rate constant for pseudo-first-order biosorption $\left(\mathrm{min}^{-1}\right)$. Plotting $\log \left(q_{e}-q_{t}\right)$ against $t$ allows us to determine the applicability of the pseudo-first-order kinetics model shown in Equation 3 to the experimental data.

The pseudo-first-order kinetics models for the removal of DR by the four types of biomass tested are shown in Figure 2.
It can be seen from Fig. 2 that the pseudo-first-order kinetics model did not fit the experimental results very well. The calculated and experimental $q_{\text {eq }}$ values were significantly different for each type of biomass, the experimental $q_{\text {eq }}$ values being much higher than the calculated $q_{\text {eq }}$ values. The DR removal reaction cannot therefore be considered to follow pseudo-first-order kinetics. This could be because the boundary layer may control the early part of the removal process (Vijayaraghavan et al., 2006; Kushwaha and Sudhakar, 2013). The pseudo-first-order kinetics model has been found not to fit experimental data well over the whole contact period in most similar cases but was found to be generally applicable in the first 20-30 min of the removal processes (Ho and McKay, 1999; Varank et al., 2012).

\subsubsection{Pseudo-second-order kinetics model}

The pseudo-second-order kinetics equation, based on the biosorption equilibrium capacity, can be expressed in the form shown in Equation 4 (Ho and McKay, 1999).

$$
\frac{d_{q t}}{q_{t}}=k_{2}\left(q_{e q}-q_{t}\right)^{2}
$$

Integrating Equation 4 and applying the initial conditions gives the linear form of the pseudo-second-order kinetics model shown in Equation 5.

$$
\frac{\mathrm{t}}{\mathrm{q}_{\mathrm{t}}}=\frac{1}{\mathrm{k}_{2} \mathrm{q}_{\mathrm{e}}^{2}}+\left(\frac{1}{\mathrm{q}_{\mathrm{e}}}\right) \mathrm{t}
$$

The initial biosorption rate, $h\left(\mathrm{mg}\left(\mathrm{g} \mathrm{min}^{-1}\right)\right.$ is defined as shown in Equation 6.

$$
h=k_{2} q_{e}^{2}
$$


Table 1. The pseudo-first-order, pseudo-second-order, intraparticle diffusion, Elovich, and Bangham model rate constants

\begin{tabular}{|c|c|c|c|c|c|c|c|c|c|c|c|c|c|c|c|c|c|}
\hline \multirow[b]{2}{*}{ Temp. $\left({ }^{\circ} \mathrm{C}\right)$} & \multirow[b]{2}{*}{$\operatorname{Exp} . q_{\mathrm{e}}(\mathrm{mg} / \mathrm{g})$} & \multicolumn{3}{|c|}{ First-order kinetic model } & \multicolumn{3}{|c|}{ Second-order kinetic model } & \multicolumn{4}{|c|}{ Intra particle diffusion model } & \multicolumn{3}{|c|}{ Elovich model } & \multicolumn{3}{|c|}{ Bangham's model } \\
\hline & & $q_{\mathrm{e}}(\mathrm{mg} / \mathrm{g})$ & $K_{1}\left(\min ^{-1}\right)$ & $\boldsymbol{R}_{1}^{2}$ & $q_{\mathrm{e}}(\mathrm{mg} / \mathrm{g})$ & $\begin{array}{c}K_{2} \\
\left(\mathrm{~g} / \mathrm{mg} \mathrm{min}^{-1}\right) \\
\end{array}$ & $R_{2}^{2}$ & $\begin{array}{c}K_{p 1} \\
\left(\mathrm{mg} / \mathrm{g} \cdot \mathrm{min}^{0.5}\right)\end{array}$ & $R_{1}^{2}$ & $\begin{array}{c}K_{p 2} \\
\left(\mathrm{mg} / \mathrm{g} \cdot \mathrm{min}^{0.5}\right)\end{array}$ & $R_{2}^{2}$ & $\alpha(\mathrm{mg} / \mathrm{g} \cdot \mathrm{min})$ & $B(\mathrm{~g} / \mathrm{mg})$ & $R^{2}$ & $k_{o}(g)$ & $\alpha$ & $R^{2}$ \\
\hline \multicolumn{18}{|l|}{ MMRS } \\
\hline 20 & 29.34 & 2.63 & $7.37 \times 10^{-3}$ & 0.98 & 29.58 & $7.22 \times 10^{-3}$ & 0.99 & 0.7169 & 0.92 & 0.0811 & 0.66 & $1.05 \times 10^{2}$ & 0.3727 & 0.87 & 6.949 & 0.185 & 0.87 \\
\hline 30 & 30.78 & 3.27 & $6.21 \times 10^{-3}$ & 0.83 & 31.05 & $8.42 \times 10^{-3}$ & 0.99 & 0.8372 & 0.89 & 0.0429 & 0.98 & $1.64 \times 10^{2}$ & 0.3696 & 0.79 & 7.623 & 0.188 & 0.79 \\
\hline 40 & 30.02 & 6.98 & $9.67 \times 10^{-3}$ & 0.73 & 30.12 & $1.18 \times 10^{-2}$ & 0.99 & 2.8552 & 0.97 & 0.0276 & 0.66 & $5.54 \times 10^{12}$ & 1.2285 & 0.61 & 17.40 & 0.056 & 0.61 \\
\hline \multicolumn{18}{|l|}{ TMRS } \\
\hline 20 & 31.89 & 2.27 & $4.37 \times 10^{-3}$ & 0.96 & 32.36 & $4.33 \times 10^{-3}$ & 0.99 & 0.6122 & 0.93 & 0.1064 & 1.00 & $9.18 \times 10^{1}$ & 0.3355 & 0.88 & 6.344 & 0.207 & 0.88 \\
\hline 30 & 26.20 & 4.26 & $5.98 \times 10^{-3}$ & 0.90 & 26.31 & $1.06 \times 10^{-2}$ & 0.99 & 0.76 & 1.00 & 0.1028 & 0.81 & $7.28 \times 10^{6}$ & 0.8755 & 0.90 & 1.055 & 0.078 & 0.90 \\
\hline 40 & 29.94 & 3.20 & $9.21 \times 10^{-3}$ & 0.73 & 30.12 & $1.40 \times 10^{-2}$ & 0.99 & 2.6385 & 0.95 & 0.1507 & 0.53 & $5.17 \times 10^{4}$ & 0.5876 & 0.79 & 11.29 & 0.117 & 0.79 \\
\hline \multicolumn{18}{|l|}{ MM17 } \\
\hline 20 & 25.56 & 5.17 & $2.07 \times 10^{-3}$ & 0.48 & 25.44 & $2.26 \times 10^{-2}$ & 0.99 & 1.0996 & 0.93 & 0.0602 & 0.31 & $3.55 \times 10^{1}$ & 0.3893 & 0.76 & 5.536 & 0.185 & 0.74 \\
\hline 30 & 23.25 & 2.51 & $4.83 \times 10^{-3}$ & 0.86 & 23.52 & $8.76 \times 10^{-3}$ & 0.99 & 1.3231 & 0.98 & 0.1713 & 0.84 & $1.11 \times 10^{3}$ & 0.5916 & 0.90 & 6.484 & 0.122 & 0.90 \\
\hline 40 & 24.33 & 1.40 & $4.83 \times 10^{-3}$ & 0.84 & 25.06 & $3.58 \times 10^{-3}$ & 0.99 & 1.9003 & 0.87 & 0.3866 & 0.82 & $0.88 \times 10^{1}$ & 0.3448 & 0.74 & 3.307 & 0.217 & 0.74 \\
\hline \multicolumn{18}{|l|}{ TM17 } \\
\hline 20 & 39.41 & 17.14 & $9.21 \times 10^{-4}$ & 0.09 & 38.61 & $5.80 \times 10^{-1}$ & 0.99 & 5.3467 & 1.00 & 0.0495 & 0.27 & $6.52 \times 10^{24}$ & 1.6869 & 0.54 & 34.28 & 0.103 & 0.48 \\
\hline 30 & 39.02 & 5.59 & $4.83 \times 10^{-3}$ & 0.55 & 39.06 & $1.19 \times 10^{-1}$ & 0.99 & 2.7916 & 0.95 & 0.1016 & 0.76 & $1.59 \times 10^{10}$ & 0.7821 & 0.89 & 19.71 & 0.169 & 0.93 \\
\hline 40 & 17.64 & 3.54 & $3.68 \times 10^{-3}$ & 0.61 & 17.73 & $2.42 \times 10^{-2}$ & 0.99 & 1.4695 & 0.96 & 0.0819 & 0.95 & $7.51 \times 10^{4}$ & 1.1890 & 0.94 & 6.313 & 0.069 & 0.94 \\
\hline
\end{tabular}




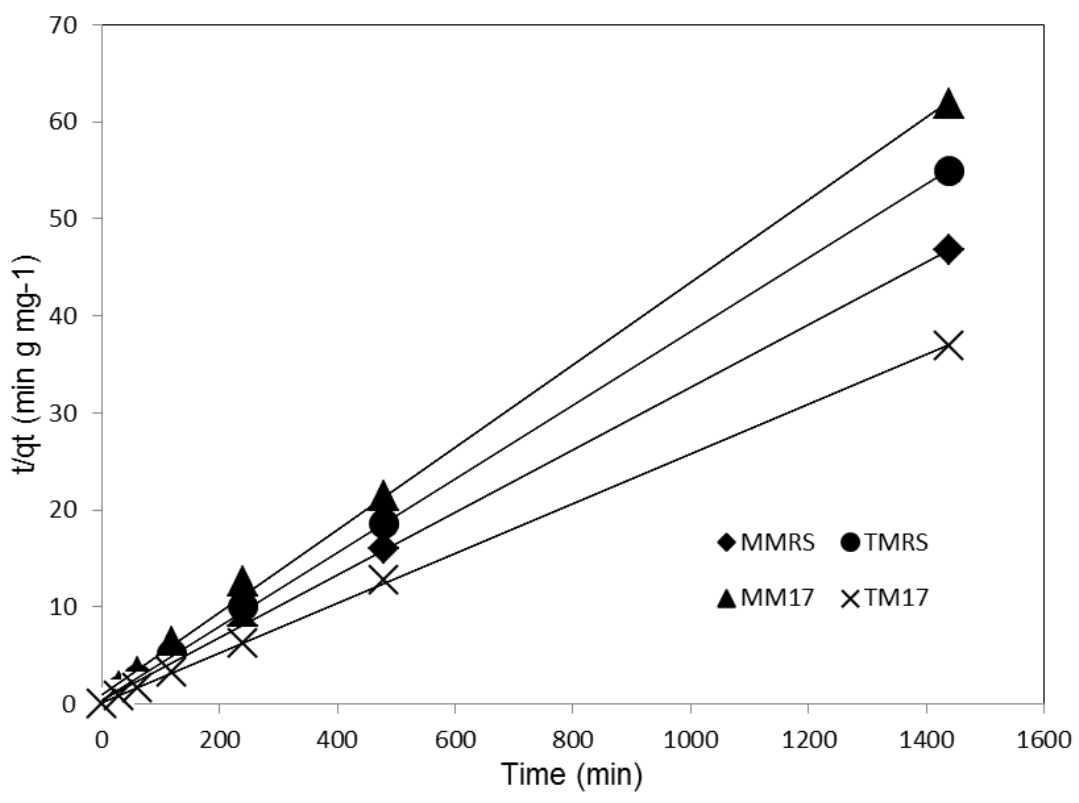

Figure 2. Pseudo-first-order kinetics model plots for the biosorption data for the removal of Dorasyn Red by the biomass samples. The dye concentration was $100 \mathrm{mg} \mathrm{L}^{-1}$, the biomass dose was $2.5 \mathrm{~g} \mathrm{~L}^{-1}$, the solutions were at $\mathrm{pH} 3$, and the temperature was $30^{\circ} \mathrm{C}$

Plotting $t / q_{t}$ against $t$ produces a line, the slope and intercept of which are the biosorption capacity at equilibrium $q_{\mathrm{e}}$ and $k_{2}$, respectively. In Equation $5, h, q_{e}(\mathrm{mg}$ $\left.\mathrm{g}^{-1}\right)$, and $k_{2}\left(\mathrm{~g}(\mathrm{mg} \mathrm{min})^{-1}\right)$ are the initial adsorption rate, the biosorption capacity at equilibrium, and the equilibrium rate constant, respectively, for pseudo-second-order biosorption.
The pseudo-second-order kinetics model fitted the experimental data well, a plot of $t / q_{t}$ against $t$ giving a straight line for each type of biomass (Fig. 3) and the correlation coefficients being very high (>0.99).

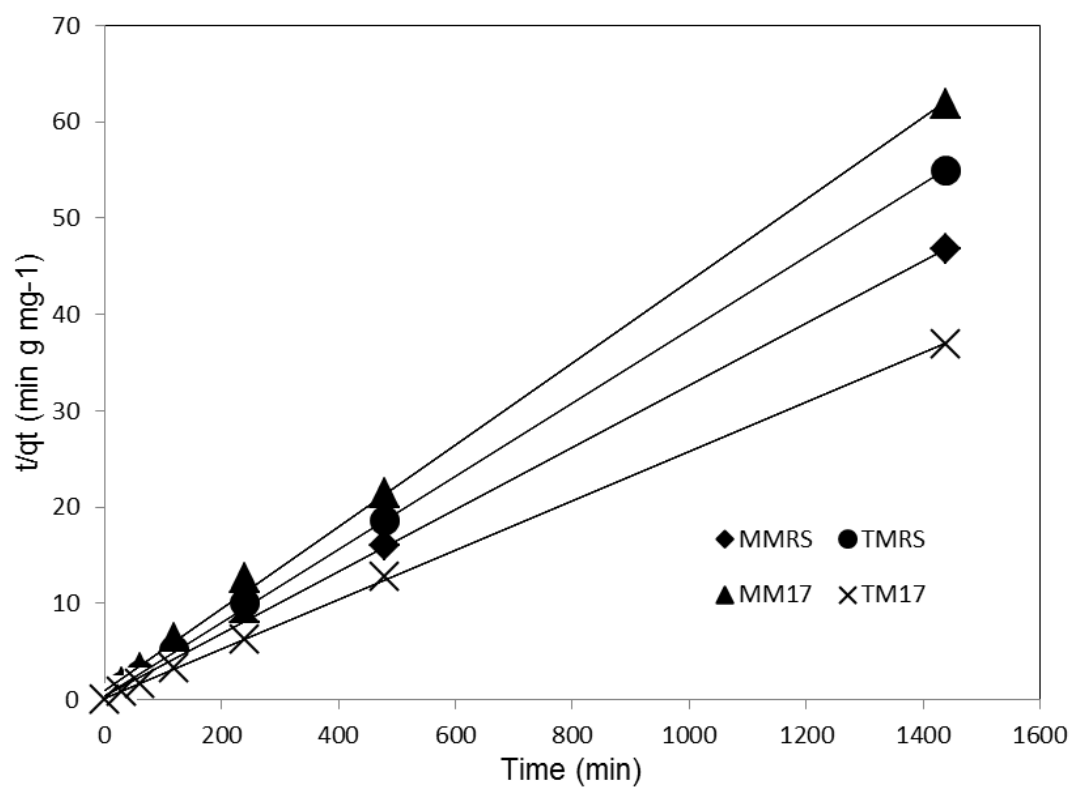

Figure 3. Pseudo-second-order kinetics model plots for the biosorption data for the removal of Dorasyn Red by the biomass samples. The dye concentration was $100 \mathrm{mg} \mathrm{L}^{-1}$, the biomass dose was $2.5 \mathrm{~g} \mathrm{~L}^{-1}$, the solutions were at $\mathrm{pH} 3$, and the temperature was $30^{\circ} \mathrm{C}$.

The $q_{e}$ values were similar $\left(25-30 \mathrm{mg} \mathrm{g}^{-1}\right)$ at all of the temperatures that were used $\left(20-40{ }^{\circ} \mathrm{C}\right)$. The calculated $q_{\mathrm{eq}}$ values for each type of biomass at each temperature tested were very similar to the experimental $q_{\text {eq }}$ values. These results suggest that the biosorption process was described well by the pseudo-second-order kinetics model, and this may be because the rate at which the DR was sorbed by the biomass samples was controlled by a number of 
biosorption mechanisms, as has been reported by other researchers (Chen and Wang 2007, Varank et al., 2012).

The pseudo-second-order kinetics results showed that the initial adsorption rate $(h)$ for the MMRS and TMRS samples increased as the temperature increased. These results show that the biosorption mechanism played an important role in controlling the rate at which the DR was sorbed by the MMRS and TMRS. Yakout and Elsherif, (2010) found similar results for the sorption of strontium by rice-straw carbon. The biosorption mechanism could be the rate limiting step because of the valence forces caused by the sharing or exchange of electrons between the biomass and the dye (Saeed et al., 2005; Sangi et al., 2008).

\subsubsection{Intraparticle diffusion model}

In general, the removal of a dye from a solution proceeds via four steps, (i) bulk diffusion, (ii) film diffusion, (iii) intraparticle or pore diffusion, and (iv) a chemical reaction involved in the ion-exchange, complexation, and/or chelation of the dye (Cheung et al., 2007; Nethaji and Sivasamy, 2011). The sorption process is usually controlled by either the mass transport rate in the liquid phase or the intraparticle mass transport rate. The intraparticle diffusion model is frequently used to determine the nature of the rate-controlling step, and this model can be represented as described by Weber and Morris, (1963) and shown in Equation 7,

$$
\mathrm{q}_{\mathrm{t}}=\mathrm{k}_{\mathrm{p}} \mathrm{t}^{0.5}+\mathrm{c}
$$

where $q_{t}$ is the adsorption capacity (in $\mathrm{mg} \mathrm{g}^{-1}$ ) at time $t, k_{p}$ is the intraparticle diffusion rate constant $\left(\mathrm{mg} \mathrm{g}^{-1} \mathrm{~min}^{-0.5}\right)$, and $c$ is the intercept, which is related to the thickness of the boundary layer. The intercept and slope of the line found by plotting $q_{t}$ against $t^{0.5}$ are $c$ and $k_{p}$, respectively.

The line will pass through the origin if intraparticle diffusion is the controlling step (Nethaji and Sivasamy, 2011), but our plots contained multiple lines, indicating that two or three steps were involved in the biosorption process. The first linear portion was attributed to the immediate use of the most readily available sites on the surfaces of the biomass, and this process would have been controlled by boundary layer diffusion. The second linear portion was attributed to very slow diffusion of the DR from the surface sites into the inner pores, termed intraparticle diffusion (Chakrapani et al., 2010). The $K_{p 1}$ and $R_{1}{ }^{2}$ values were calculated for the first parts of the lines in the intraparticle diffusion model plots and the $K_{p 2}$, and $R_{2}{ }^{2}$ values were calculated for the second parts of the lines in the plots (Fig.4).

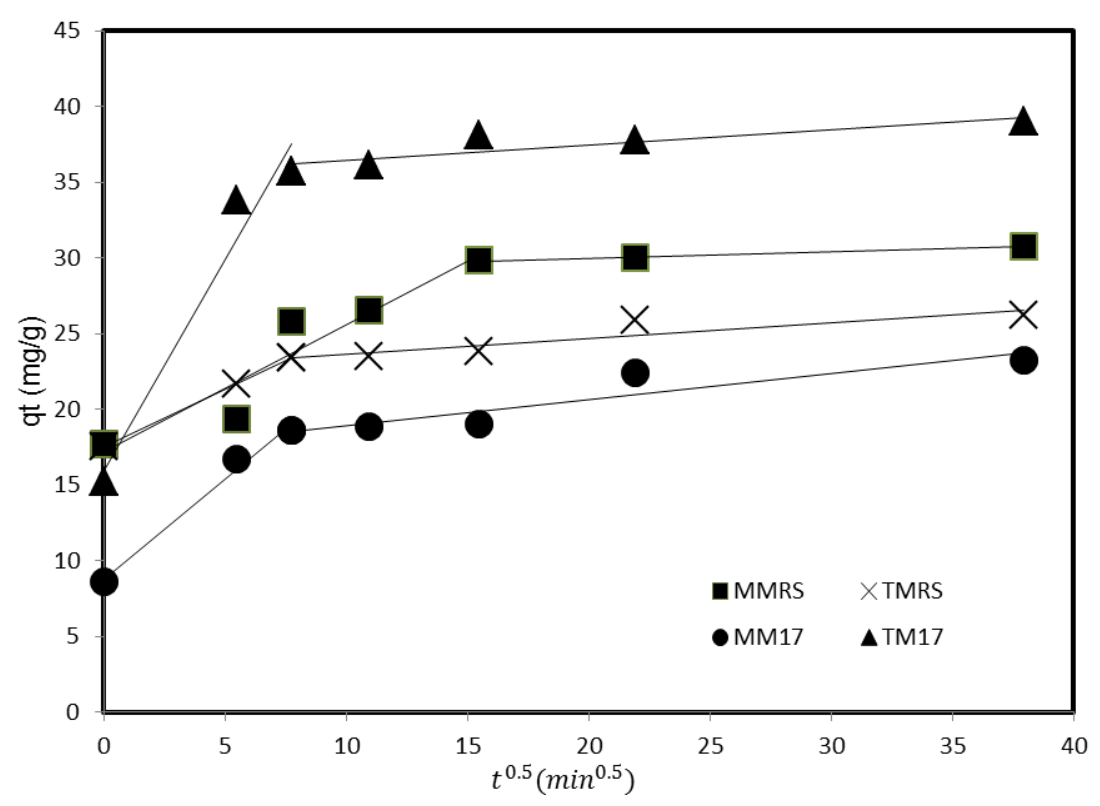

Figure 4. Intraparticle diffusion model plots for the biosorption data for the removal of Dorasyn Red by the biomass samples. The dye concentration was $100 \mathrm{mg} \mathrm{L}^{-1}$, the biomass dose was $2.5 \mathrm{~g} \mathrm{~L}^{-1}$, the solutions were at $\mathrm{pH} 3$, and the temperature was $30^{\circ} \mathrm{C}$.

The correlation coefficients for the first portions of the lines $\left(R_{1}{ }^{2}\right)$ were $0.87-1.00$, and the correlation coefficients for the second portions of the lines $\left(R_{2}^{2}\right)$ were $0.31-1.00$. The $R_{1}{ }^{2}$ values were higher than the $R_{2}^{2}$ values, indicating that boundary layer diffusion played an importing role in controlling the biosorption rate. These results indicate that intraparticle diffusion was not the only rate-controlling step, but that boundary layer diffusion also played a role in controlling the rate, and this is consistent with previous reports (Batzias and Sidiras, 2007; Nethaji and Sivasamy, 2011).

\subsubsection{Elovich kinetics model}

The Elovich kinetics equation has been used to describe the adsorption of a solute from an aqueous solution (Bulut and Özacar, 2008). This equation is also used to describe second order kinetics assuming that the solid surfaces are energetically heterogeneous. However, no specific sorption mechanism has been associated with this model (Sparks, 1989).

The linear form of the Elovich equation (Sparks, 1989) is shown in Equation 8, 


$$
\mathrm{q}_{\mathrm{t}}=\frac{1}{\beta} \ln (\alpha \beta)+\frac{1}{\beta} \ln \mathrm{t}
$$

where $\alpha\left(\mathrm{mg}\left(\mathrm{g} \mathrm{min}^{-1}\right)\right.$ is the initial sorption rate and $\beta\left(\mathrm{g} \mathrm{mg}^{-1}\right)$ is related to the surface coverage and the chemisorption activation energy. The Elovich coefficients can be calculated from the line found when $q_{t}$ is plotted against $\ln (t)$, as shown for our data in Figure 5 .

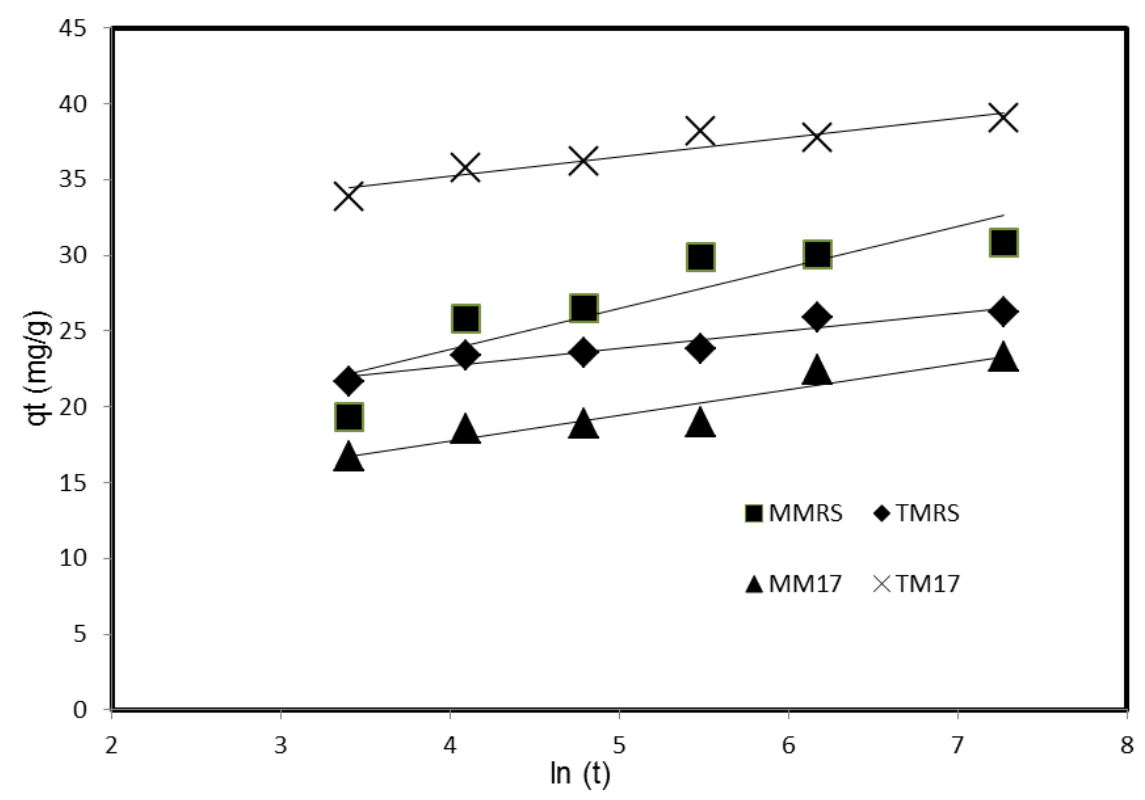

Figure 5. Elovich model plots for the biosorption data for the removal of Dorasyn Red by the biomass samples.

The dye concentration was $100 \mathrm{mg} \mathrm{L}^{-1}$, the biomass dose was $2.5 \mathrm{~g} \mathrm{~L}^{-1}$, the solutions were at $\mathrm{pH} 3$, and the temperature was $30^{\circ} \mathrm{C}$

The $\alpha$ value generally increased as the temperature increased for both the MMRS and TMRS. The $\alpha$ value for the MMRS was $1.05 \times 10^{2}$ at $20^{\circ} \mathrm{C}$, and it increased to about $5.54 \times 10^{12}$ at $40^{\circ} \mathrm{C}$. These results indicate that the roles of the biosorption mechanisms in controlling the uptake rate increased with temperature, which is consistent with the results of previous studies (Aksakal and Ucun, 2010; Yakout and Elsherif, 2010). However, the Elovich model did not fit the experimental data well for all the biomass samples that were tested $\left(R^{2}=0.54-0.90\right)$.

\subsubsection{Bangham's model}

We attempted to determine whether a slow uptake step (pore diffusion) occurred in the adsorption system using Bangham's equation (Aharoni et al., 1979), which is shown in Equation 9.

$$
\log \log \left(\frac{c_{0}}{c_{0}-q_{t} m}\right)=\log \left(\frac{k_{0} m}{2.303 V}\right)+\alpha \log t
$$

In Equation 9, $\mathrm{c}_{0}$ is the initial concentration ( $\mathrm{mg} \mathrm{L}^{-1}$ ) of the dye in the solution, $V$ is the volume of the solution $(\mathrm{mL}), m$ is the concentration ( $\mathrm{g} \mathrm{L}^{-1}$ ) of the adsorbent (biomass), and $q_{t}$ is the amount of dye adsorbed $\left(\mathrm{mg} \mathrm{g}^{-1}\right)$ at a specific time. The constants $\alpha(<1)$ and $k_{0}$ are the intercept and slope, respectively, of the line found when $\log \left(c_{0} / c_{0}-q_{t} m\right)$ is plotted against $\log (t)$, as shown for each type of biomass tested in Fig. 6.

The correlations were not good for the biomass samples tested at any of the temperatures used (the $R^{2}$ values were $0.48-0.94)$. These results indicate that pore diffusion was not the only rate-controlling step in the DR removal process. Kuswaha and Sudhakar, (2013) and Varank et al., (2012) found similar results in studies of the sorption of uranium and 4-nitrophenol, respectively.

\section{Conclusions}

Kinetics experiments showed that the mesophilic biomasses (MMRS and MM17) removed the DR effectively at 20,30 , and $40^{\circ} \mathrm{C}$. The kinetics data acquired for all four types of biomass at three different temperatures were investigated using pseudo-first-order kinetics, pseudosecond-order kinetics, intraparticle diffusion, Elovich, and Bangham models, and the biosorption process was found to follow pseudo-second-order kinetics and the first stage of the intraparticle diffusion model. We concluded that the biosorption of DR by the biomass samples tested involves a number of mechanisms, and that boundary layer diffusion has a particularly marked effect on the biosorption rate. 


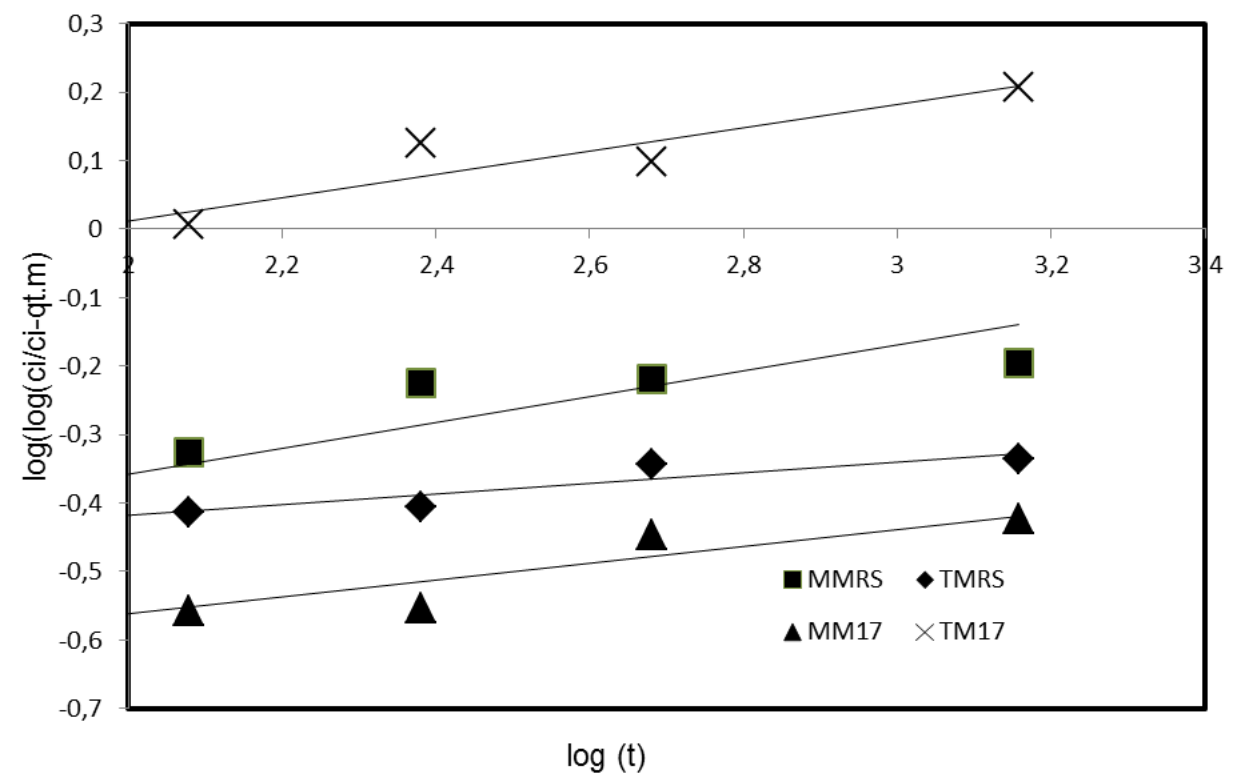

Figure 6. Bangham's model plots for the biosorption data for the removal of Dorasyn Red by the biomass samples. The dye concentration was $100 \mathrm{mg} \mathrm{L}^{-1}$, the biomass dose was $2.5 \mathrm{~g} \mathrm{~L}^{-1}$, the solutions were at $\mathrm{pH} 3$, and the temperature was $30^{\circ} \mathrm{C}$.

\section{Acknowledgements}

The author thanks to Dr.Aytül Sofu for supplying the chemicals and preparing the biomasses.

\section{References}

Aharoni C., Sideman S. and Hoffer E. (1979), Adsorption of phosphate ions by collodion-coated alumina, J of Chem Tech and Biotech, 29(7), 404-412.

Akar T. and Divriklioglu M. (2010), Biosorption applications of modified fungal biomass for decolorization of Reactive Red 2 contaminated solutions: batch and dynamic flow mode studies, Bioresource Technol, 109, 7271-7277.

Akar T., Celik S. and Akar S.T. (2010), Biosorption performance of surface modified biomass obtained from Pyracantha coccinea for the decolorization of dye contaminated solutions, Chem Eng J, 160, 466-472.

Aksakal O. And Ucun H. (2010), Equilibrium, kinetic and thermodynamic studies of the biosorption of textile dye (Reactive Red 195) onto Pinus sylvestris L, J of Hazard Mater, 181, 666-672.

Annadurai G., Ling L.Y. and Lee J.F. (2008), Adsorption of reactive dye from an aqueous solution by chitosan: isotherm, kinetic and thermodynamic analysis, J Hazard Mater, 152, 337-346.

Asgher M. and Bhatti H.N. (2012), Evaluation of thermodynamics and effect of chemical treatments on sorption potential of Citrus waste biomass for removal of anionic dyes from aqueous solutions, Ecolog Eng, 38, 79-85.

Banks C.J. and Parkinson M.E. (1992), The mechanism and application of fungal biosorptionto color removal from raw waters, J Chem Technol Biotechnol, 54, 192-196.

Baskaralingam P., Pulikes M., Elango D., Ramamurthi V. and Sivanesan S. (2006), Adsorption of acid dye onto organobentonite, J Hazard Mater, B128, 138-144.

Batzias F.A. and Sidiras D.K. (2007), Dye adsorption by prehydrolysed beech sawdust in batch and fixed-bed systems, Bioresour Technol, 98, 1208-1217.
Bulut E. and Özacar M. (2008), Adsorption of malachite green onto bentonite: equilibrium and kinetic study and process design, Micropor Mesopor Mater, 115, 234-246.

Chakrapani C.H., Babu C.H.S., Vani K.N.K. and Rao K.S. (2010), Adsorption kinetics fort he removal of fluoride from aqueous solution by activated carbon adsorbents derived from the peels of selected citrus fruits, E-Jour of Chem, 7(S1), 419-427.

Chen H. and Wang A.Q. (2007), Kinetic and isothermal studies of lead ions adsorption onto palygorskite clay, J. Colloid Interface Sci, 307, 309-316.

Cheung R., Qu S., Li S. and Xiang B. (2009), Intraparticle diffusion processes during acid dye adsorption onto chitosan, Bioresour Technol, 98, 2897-2904.

Chu H.C. and Chen K.M. (2002), Reuse of activated sludge biomass: I. Removal of basicdyes from wastewater by biomass, Process Biochem, 37, 595-600.

Deive F.J., Dominguez A., Barrio T., Moscoso F., Moran P., Longo M.A. and Sanroman M.A. (2010), Decolorization of dye Reactive Black 5 by newly isolated thermophilic microorganisms from geothermal sites in Galicia (Spain), J Hazard Mater, 182, 735-742.

Deveci H., Akcil A. and Alp I. (2004), Bioleaching of complex zinc sulphides using mesophilic and thermophilic bacteria: comparative importance of $\mathrm{pH}$ and iron, Hydrometallurgy, 73, 293-303.

Fan H., Yang J.S., Gao T.G. and Yuan H.L. (2012), Removal of a lowmolecular basic dye (Azure Blue) from aqueous solutions by a native biomass of a newly isolated Cladosporium sp.: Kinetics, equilibrium and biosorption simulation, J Taiwan Inst of Chem Eng, 43, 386-392.

Gupta V.K. and Suhas (2009), Application of low-cost adsorbents for dye removal - A review, J of Environ Manage, 90, 2313-2342.

Ho Y.S. and McKay G. (1998), A comparison of chemisorption kinetic models applied to pollutant removal on various sorbents, Process Saf. Environ. Protection, 76(B4), 332-340. 
Ho Y.S. and McKay G. (1999), Pseudo-second order model for sorption processes, Process Biochem, 34(5), 451-465.

Kaushik P. and Malik A. (2011), Process optimization for efficient dye removal by Aspergillus lentulus FJ172995, J Hazard Mater, 185, 837-843.

Kurade M.B., Waghmode T.R., Kagalkar A.N. and Govindwar S.P. (2012), Decolorization of textile industry effluent containing disperse dye Scarlet RR by a newly developed bacterial-yeast consortium BL-GG, Chem Eng J, 184, 33-41.

Kushwaha S. and Sudhakar P.P. (2013), Sorption of uranium from aqueous solutions using palm-shell-based adsorbents: a kinetic and equilibrium study, J of Environ. Radioactivity, 126, 115-124.

Lata H., Garg V.K. and Gupta R.K. (2008), Adsorptive removal of basic dye by chemically activated Parthenium biomass: equilibrium and kinetic modeling, Desalination, 219, 250-261.

Liu R., Liu X., Tang H. and Su Y. (2001), Sorption behavior of dye compounds onto natural sediment of Qinghe River, J Colloid Interface Sci, 239, 475-82.

Mahanpoor K., Soufi A. and Adineh J. (2005), Removal of anthraquinone dye Acid blue 41 from an aqueous solution by Aspergillus niger mycelia. The 4th National Biotechnology Congress, 3p, Iran.

Mona S., Kaushik A. and Kaushik C.P. (2011), Biosorption of reactive dye by waste biomass of Nostoc linckia, Ecol Eng, 37, 1589- 1594.

Nethaji S. and Sivasamy A. (2011), Adsorptive removal of an acid dye by lignocellulosic waste biomass activated carbon: Equilibrium and kinetic studies, Chemosphere, 82, 1367-1372.

Oturkar C.C., Harshal N.N., Muli, P.M., Patole M.S., Hawaldar R.R. and Gawai K.R. (2011), Mechanistic investigation of decolorization and degradation of Reactive Red 120 by Bacillus lentus BI377, Bioresource Technol, 102, 758-764.

Parshetti G.K., Telke A.A., Kalyani D.C. and Govindwa S.P. (2010), Decolorization and detoxification of sulfonated azo dye methyl orange by Kocuria rosea MTCC 1532, J Hazard Mater, 176, 503-509.

Pearce C.I., Lloyd J.R. and Guthrie J.T. (2003), The removal of colour from textile wastewater using whole bacterial cells: a review, Dyes Pigments, 58, 179-196.

Pengthamkeerati P., Satapanajaru T. and Singchan O. (2008), Sorption of reactive dye from aqueous solution on biomass fly ash, J Hazard Mater, 153, 1149-1156.

Ramyakrishna K. and Sudhamani M. (2017), The metal binding potential of a dairy isolate, J of Water Reuse and Desalination, 7(4), 429-441.

Saeed A., Akhtar M.W. and Iqbal M. (2005), Removal and recovery of heavy metals from aqueous solution using papaya wood as a new biosorbent, Separation and Purif Technol, 45, 25-31.

Sangi M.R., Shahmoradi A., Zolgharnein J., Azimi G.H. and Ghorbandoost M. (2008), Removal and recovery of heavy metals from aqueous solution using Ulmus carpinifolia and Fraxinus excelsior tree leaves, J Hazard Mater, 155(3), 513-522.

Sayilgan E. and Cakmakci O. (2013), Treatment of textile dyeing wastewater by biomass of Lactobacillus: Lactobacillus 12 and Lactobacillus rhamnosus, Environmen Sci Poll Res, 20(3), 1556-1564.

Seesuriyacha P., Takenaka S., Kuntiya A., Klayraung S., Murakami S. and Aoki K. (2007), Metabolism of azo dyes by Lactobacillus casei TISTR 1500 and effects of various factors on decolorization, Water Res, 41, 985-992.

Sofu A., Sayilgan E. And Guney G. (2015), Experimental design for removal of $\mathrm{Fe}(\mathrm{II})$ and $\mathrm{Zn}$ (II) ions by different lactic acid bacteria biomasses, J. Environ. Res, 9(1), 93-100.

Sparks,D.L. (1989), Kinetics of soil chemical processes, Academic Press, New York.

Taha M., Adetutu E.M., Shahsavari E., Smith A.T. and Ball A.S. (2014), Azo and anthraquinone dye mixture decolourization at elevated temperature and concentration by a newly isolated thermophilic fungus, Thermomucor indicaeseudaticae, J Environ Chem Eng 2, 415-423.

Varank G., Demir A., Yetilmezsoy K., Top S., Sekman E. and Bilgili M.S. (2012), Removal of 4-nitrophenol from aqueous solution by natural low-cost adsorbents, Indian J of Chem Tech, 19, 725.

Vijayaraghavan K., Palanivelu K. and Velan M. (2006), Biosorption of copper(II) and cobalt(II) from aqueous solutions by crab Shell particles, Biores Technol, 97, 1411-1419.

Weber J.W. and Morris J. (1963), Kinetics of adsorption on carbon from solution, J Sanit Eng, ASC 89, 31-59.

Xi Y., Shen Y.F., Yang F., Yang G., Liu C., Zhang Z. and Zhu D.H. (2013), Removal of azo dye from aqueous solution by a new biosorbent prepared with Aspergillus nidulans cultured in tobacco wastewater, J Taiwan Inst Chem Eng, 44, 815-820.

Yakout S.M. and Elsherif E. (2010), Batch kinetics, isotherm and thermodynamic studies of adsorption of strontium from aqueous solutions onto low cost rice-straw based carbons, Carbon - Sci Tech, 1, 144-153.

Zhang Z., Xia S., Wang X., Yang A., Xu B., Chen L., Zhu Z., Zhao J., Jaffrezic-Renault N. and Leonard D. (2009), A novel biosorbent for dye removal: extracellular polymeric substance (EPS) of Proteus mirabilis TJ-1, J Hazard Mater, 163, 279-284. 